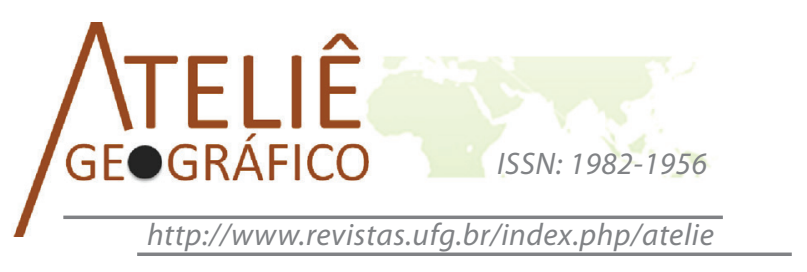

\title{
Educação ambiental no âmbito do Sistema Colégio Militar do Brasil
}

\author{
Environmental education on the Sistema Colégio Militar \\ do Brasil
}

Educación ambiental en Sistema Colégio Militar de Brasil

\author{
Adriano Bittencourt Andrade \\ Universidade de Brasília \\ E-mail: abittandrade@hotmail.com \\ Cláudia Cristina Silveira da Luz \\ Universidade Católica de Brasília \\ claudiakauluz@gmail.com
}

\begin{abstract}
Resumo
Esse artigo apresenta como se dá o enfrentamento da temática ambiental no Ensino Médio ( $1^{\circ}$ a $3^{\circ}$ Anos) no âmbito do Sistema Colégio Militar do Brasil. O texto se posiciona diante da dicotomia entre o agravamento da crise ambiental associada à dependência de recursos não renováveis com aumento exponencial da emissão de resíduos (tanto no momento da produção como no consumo) e, do outro lado, o aprofundamento das discussões, ampliação do conhecimento sobre as dinâmicas naturais e a disseminação da educação ambiental. À luz desse cenário contraditório, o artigo historiciza a crise ambiental, notadamente no contexto do Brasil da nossa contemporaneidade, e avalia como que os Planos Curriculares Nacionais se posicionam na orientação para o trato dessa temática. Mais especificamente, como core do trabalho, o texto faz uma análise dos programas de Geografia nos Colégios Militares identificando os avanços, limites e possibilidades referentes ao trato do assunto meio ambiente.
\end{abstract}

Palavras-chave: Crise Ambiental. Educação Ambiental. Planos Curriculares Nacionais. Sistema Colégio Militar do Brasil.

\footnotetext{
Abstract

This paper presents how the Environmental Education is seen in the High School years at the Brazilian Military School System. It analyses the dichotomy between the exacerbation of the environmental crisis, associated to the dependency of
} 
renewable and not renewable resources, and the exponential increase of wastes (when producing as well as consuming), and in the other side the deep discussions, expansion of knowledge on the natural dynamics and the dissemination of the environmental education. Considering this contradictory scenario, this paper brings the history of the environmental crisis, especially in the contemporary Brazilian contexts and, evaluates how the Plan of National Curricular Guidelines lead with the theme of environmental education. More precisely, the common core of the paper, it analyses the Brazilian Military School System Geography curricula programes concerning on the environmental issue, identifying the advances, limits and possibilities.

Keywords: Environmental crisis. Environmental Education. Plan of National Curricular Guidelines. The Brazilian Military School System.

\begin{abstract}
Resumen
En este artículo se muestra cómo es el enfrentamiento de los problemas ambientales en la escuela secundaria ( $1^{\circ}$ a $3^{\circ}$ años) bajo el Sistema Colegio Militar de Brasil. El texto se coloca ante la dicotomía entre la crisis ambiental asociada con la dependencia de los recursos no renovables con un aumento exponencial de la emisión de residuos (tanto en el momento de la producción y el consumo) y, por otro lado, la profundización de la discusión, la expansión de los conocimientos sobre la dinámica natural y la difusión de la educación ambiental. A la luz de esta situación contradictoria, el artículo sitúa históricamente la crisis ambiental, especialmente en el contexto del Brasil contemporáneo, y evalúa cómo se posicionan los Planes Nacionales Curriculares en la orientación para hacer frente a este problema. Más específicamente, c omo e $1 \mathrm{t}$ rabajo e sencial, e 1 t exto a naliza 1 os programas de Geografía en Colegios Militares, identifica 1 os a vances, 1 as 1 imitaciones y posibilidades para el tratamiento de la cuestión ambiental.
\end{abstract}

Palabras clave: Crisis Ambiental. Educación Ambiental. Planes Nacionales Curriculares. Sistema Colegio Militar de Brasil.

Voltei a ter aquela sensação que há algum tempo denominei de 'falar para o espelho'. Vi muita gente boa, bem informada, especializada, mas revelando certo cansaço de falar e ouvir as mesmas coisas com tão pouco resultado prático.

Discurso de Marina Silva apud Marcovitch (2006, p.55).

\title{
Introdução
}

A temática ambiental nunca esteve em tamanha evidência como na nossa contemporaneidade. De forma oportunista ou não as preocupações ambientais se avolumaram nos últimos anos, especialmente após o primeiro grande encontro sob essa bandeira promovido pela ONU, no ano de 1972, na capital da Suécia (Estocolmo 72).

Ainda que, nesses últimos quarenta anos, a sociedade do consumo tenha se hegemonizado lançando seus tentáculos sobre todos os cantos do planeta, ampliando quantitativa e qualitativamente o consumo e, por conseguinte, a produção de resíduos. Ainda que a dependência dos recursos naturais de origem fóssil (tanto como matéria 
prima como para fins energéticos) tenha se aprofundado. Ainda que a população global tenha chegado à impressionante marca de mais de 6 bilhões de pessoas e continue num ritmo ascendente de crescimento demográfico mundial, impulsionando a inclusão pelo viés capitalista do consumo e, consequentemente, lançando sobrecarga aos recursos naturais. Ainda que os desastres que agridem o meio ambiente e as notícias de problemas relacionados à relação do homem com a natureza não parem de aparecer na mídia. Ainda que a discussão ambiental, por vezes, pareça cada vez mais inócua, ainda assim, ou até por isso mesmo, as notícias sobre a atual crise ambiental nunca estiveram tão presentes quanto agora.

Na tentativa de explicar por esse viés as variadas catástrofes socioambientais que pululam mundo afora, uma série de eventos relacionados dão o volume à essa temática, a exemplo da multiplicação de ONGs (sociedade civil organizada que atual e fiscaliza o primeiro e segundo setores - Estado e iniciativa privada), o crescimento das estratégias de controle ambiental (o mais conhecido é o selo de certificação da série 14.000), a ação dos governos e entidades supranacionais proporcionando palcos de debate institucional sobre o meio ambiente (o mais recente exemplo é certamente o Rio +20 ). Coadunando com essa expansão da temática ambiental e dando visibilidade ao assunto, aumentam também as publicações dentro e fora da academia (nunca houve, no âmbito do Brasil, tantos cursos universitários e de pós graduação com o tema meio ambiente) e uma ação global da mídia que explora o assunto nas mais diversas formas (filmes, a exemplo dos recentes "Um dia depois de amanhã" ou "Uma verdade inconveniente", manchetes e matérias em variados veículos criando emblemas ambientais que se transformam em marketing positivo, etc.) transformando em notícia e, evidentemente, em audiência e lucro.

Esse contexto supramencionado apresenta um imenso contra senso. Tem-se, por um lado, o aprofundamento dos principais problemas derivados da exploração de recursos naturais, produção de resíduos de toda ordem e exclusão de grande parte da população mundial que vive em condições subumanas; por outro lado, o desenvolvimento nas pesquisas e a presença do discurso ambiental chega a um número cada vez maior de pessoas e representa, inegavelmente, um avanço. É nesse cenário dicotômico que se situa o texto desse artigo.

Objetiva-se, de forma mais ampla, analisar esse cenário posto a partir de dados e diálogos com outros autores e, de mais especificamente, avaliar como essa problemática é enfrentada no ciclo básico de educação no Brasil. Para isso, ampliando a escala de análise, trabalha-se com o caso empírico do Sistema Colégio Militar do Brasil e estabelece-se como fim avaliar como esse sistema de âmbito nacional tem enfrentado o desafio da educação ambiental na disciplina de Geografia no Ensino Médio $\left(1^{\circ}\right.$ a $3^{\circ}$ Anos).

O texto que segue está estruturado em três seções: primeiro, faz-se o exercício de sintetizar os principais marcos teóricos da crise ambiental (contexto e autores que se debruçaram sobre o assunto); depois, apresenta-se a perspectiva educacional sobre a vertente do meio ambiente, para isso se utiliza de dados históricos e das orientações dos Planos Curriculares Nacionais (PCNs); na última seção, desenvolve-se uma análise de 
como essa temática é tratada no âmbito dos Colégios Militares, apresentando avanços e desafios, notadamente no tocante ao currículo de Geografia.

Enfim, a intenção desse artigo é fazer uma revisão da literatura e estabelecer o enfrentamento entre a controversa temática ambiental e as práticas educacionais ligadas à esse tema dentro de um sistema de alcance nacional. Apesar dos óbvios limites de desenvolver tal debate no texto de um artigo científico, acredita-se que essa primeira aproximação pode render outros frutos com o aprofundamento do estudo.

\section{Contextualizando a crise ambiental}

A questão fundamental que se apresenta na nossa contemporaneidade é se há uma crise ambiental derivada da ação antrópica ou se a Terra permanece seguindo os seus ciclos naturais, entretanto, agora, submetida à presença consciente do homem que, no processo contínuo de apropriação e domínio do meio, transformou-a numa "natureza hostil" quando, nos seus eventos drásticos não se submete ao controle técnico que a sociedade lhe impõe.

O geógrafo Antônio Carlos Robert de Moraes alerta que "a história humana pode ser vista como uma progressiva apropriação da superfície terrestre pelos diferentes grupos sociais [...] riquezas naturais transformadas em objetos de consumo e de formas construídas que se agregam ao solo sobre o qual estão erguidas” (MORAES, 1997, p.35).

Tem-se então como ressalva que a degradação ambiental não pode ser entendida por si só, ou de forma isolada de um imenso contexto em que se realiza. Esse problema, assim como tantos outros da nossa contemporaneidade deve ser analisado no conjunto da configuração territorial e mesmo a interconexão entre os espaços no mundo, sob o risco de termos uma noção apenas parcial da totalidade. Nesse sentido, e ampliando o olhar sobre o discurso da atual crise ambiental, o mesmo autor escreveu que "a questão em exame passa a ser não a da unidade entre o homem e a natureza, mas a da separação entre os dois. E, tendo a unidade como natural, a separação só pode ser histórica e social" (MORAES, 1997, p.75).

Do mesmo modo que é necessário ampliar a escala espacial para estabelecer análises, também temporalmente esse é um tema perigoso se observarmos apenas sob a perspectiva da nossa vivencia cronológica. Assim Milton Santos orientou que

Sem o homem, isto é, antes da História, a natureza era uma. Continua a sê-lo, em si mesma, apesar das partições que o uso do planeta pelos homens lê infringiu. Agora, porém, há uma enorme mudança. Uma, mas socialmente fragmentada, durante tantos séculos, a natureza é agora unificada pela História, em benefício de firmas, estados e classes hegemônicas. Mas não é mais a Natureza Amiga, e o Homem também não é mais seu amigo. (SANTOS, 2007 [1992], p.36).

Essa Natureza apropriada pelo discurso hegemônico e, por conseguinte, fragmentada espacial e temporalmente, nos é apresentada de forma assombrosa,

1. Segundo Santos (2007 [1992]), na evolução técnica da sociedade, migramos de uma natureza "amiga", provedora e dominadora, para uma natureza "hostil", pois dominada e inconveniente quando foge ao controle. 
atendendo a interesses na criação de discursos competentes. Esse é um alerta nodal para quem se debruça sobre essa temática. Santos (2007 [1992], p.39) é enfático quando afirma que "se antes a natureza podia criar o medo, hoje é o medo que cria uma natureza midiática e falsa, uma parte da Natureza sendo apresentada como se fosse o Todo".

Com essa ressalva não se pretende obliterar o necessário discurso sobre os impactos das relações históricas entre homem e meio, entretanto esclarecer que, regularmente a "argumentação verde" é apropriada por interesses escusos ${ }^{2}$.

Feitas essas observações, percebe-se claramente que, na academia e, por conseguinte, nas redes de comunicação midiática globais, há duas frentes que se opõem em relação à temática ambiental. A primeira nega veementemente a participação do homem no catastrófico cenário ambiental dos nossos tempos ${ }^{3}$. A outra corrente, mais habitual, apresenta problemas atuais como legado da sociedade industrial. Assim, num tom brando, Marcos B. Carvalho comenta que

Os minerais se esgotam, os desertos avançam, a atmosfera se desconfigura, as águas apodrecem, as florestas estão sendo liquidadas etc. Sem dúvidas, a persistir este ritmo, em poucas décadas o "desconforto" terá atingido, indiscriminadamente, todos os homens. É o vislumbramento desta perspectiva catastrófica que começa a colocar a questão ecológica como a preocupação número um deste final de século (CARVALHO, 1994, p.91).

Aceitando essa segunda corrente, sob todos os riscos já postos, é necessário pensar como ela se realiza.

De forma abrangente, há uma concordância que o atual momento de crise ambiental e as possíveis decorrências sociais são derivadas de uma "velocidade destrutiva" no "atual padrão de reprodução do capital quando a fronteira tecnológica desaloja a fronteira territorial como fonte de superlucro"4. Efetivamente se dá um (des) encontro de ritmos entre a Natureza e o Humano, notadamente quando este assume a lógica de consumo e acumulação e aquela é tomada como fonte de recursos sob os quais se sustenta a produção.

O entendimento da Natureza como recurso natural (assim mesmo, segundo uma lógica e temporalidade da produção) reduz a sua importância como Meio e a amplia como insumo de reprodução do capital. Autores como Wagner Ribeiro (2001, p.145) alertam que essa apreensão do ambiente como recurso já apresenta sinais de escassez e "indicam a necessidade de se alterar o padrão de vida dos agrupamentos hegemônicos. A questão é quem perderá com essas alterações, impostas a uma base natural que beira à exaustão".

2. Santos (2007 [1992], p.38, escreveu ainda que "A mediação interessada, tantas vezes interesseira, da mídia, conduz, não raro, à doutorização da linguagem, necessária para ampliar o seu crédito, e à falsidade do discurso, destinado a ensombrear o entendimento. $\mathrm{O}$ discurso do meio ambiente é carregado dessas tintas, exagerando certos aspectos em detrimento de outros, mas, sobretudo, mutilando o conjunto"

3. Vários desses pensadores são apresentados num tom crítico em Marcovitch (2006, p.19 a 22), sob o mesmo enfoque, Blanc (2012, p.130-135) dedica um capítulo que chama de "A campanha de desinformação".

4. Cf. Moraes (1997, p.58). 


\section{O mesmo autor argumenta que}

Estamos assistindo, entretanto, à predominância do realismo político nas esferas de decisão da ordem ambiental, inclusive nas anteriores a ela. Sendo assim, torna-se difícil acreditar que ela será capaz de promover mudanças radicais no modo de vida das camadas dominantes, as responsáveis pela degradação. (RIBEIRO, 2001, p.146).

Ou seja, mesmo considerando a existência da crise ambiental e compreendendo a sua total vinculação ao sistema de produção capitalista, são poucas as possibilidades de enfrentá-la, visto que não há uma perspectiva a curto ou médio prazo de alteração significativa no modo de vida sustentado no consumo e, por conseguinte, causador dos pretensos problemas na relação homem-natureza.

Diante dessa encruzilhada, são diversos os grupos ambientalistas que surgem contestando ou apresentando alternativas à crise. Wagner Ribeiro (2001) trata dos variados "tons de verde", relacionando discursos que oscilam pelo o ambientalismo radical, de negócios, conservacionista e preservacionista, além daqueles que sugerem formas de vida menos impactantes. Outros autores ${ }^{5}$ também elencam diferentes perspectivas ou nuanças no enfrentamento dos problemas ambientais contemporâneos.

Dos mais inocentes aos mais radicais, há a clareza de que subverter essa ordem não é tarefa fácil, visto que "a redução ou estagnação das atividades econômicas, mostrase como algo impossível, levando-se em consideração a atual hegemonia da economia capitalista e a busca incessante do crescimento econômico que caracteriza esse modelo" (RAMOS, 1997, p.117). Pois o padrão capitalista de consumo determina um "modus vivendi" que, também hegemônico, leva ao agravamento dos problemas ambientais.

De tal forma se estabelece o controle pelo viés do capital que a mercantilização da natureza dilata inclusive o próprio meio como produto criando assim novas possibilidades de reprodução do capital na "onda verde". Surgem então novos mercados como o mercado do ar, da vida, da água (BECKER, 2007, p.39), apresentados, inclusive como alternativas à crise, numa clara perspectiva empreendedorista, ou num ambientalismo de negócios. Atrelando o discurso verde a setores empresariais, por vezes com a "adoção de medidas para rever seus processos produtivos, diminuir suas emissões de gases e elevar a competitividade em seus empreendimentos" (MARCOVITCH, 2006, p.29) através da produção de uma imagem politicamente, e ambientalmente, correta. O que Blanc (2012, Cap.25) trata como "Economia Verde".

Apesar da forte antagonia que há entre o ritmo da natureza e as demandas da sociedade capitalista, é notório que houve uma evolução (em volume e conteúdo) da discussão ambiental, notadamente, pós Estocolmo 72, com alguma utopia de mudança a partir do maior alcance da educação ambiental, desenvolvimento do conhecimento a partir de pesquisas em ciências e tecnologias, da disseminação da temática ambiental e de possíveis reposicionamentos políticos.

5. Moraes (1997, p.53-55), Ramos (1997, p.117), Marcovitch (2006, p.29), Becker (2007, p. 55) dentre outros. 
Moraes (1997, p.86) é incisivo ao constatar que "a questão agrária, a problemática do espaço, o tema da cotidianidade, entre outros, já apresentam bibliografia numerosa e resultados acumulados de cruzamentos interdisciplinares. A temática ambiental, contudo, foi pouco trabalhada." O autor ainda alerta que, ao longo do século XX, "os temas ambientais se subordinavam a outras lógicas [como as abordagens econômicas e geopolíticas] - que comandaram as decisões".

Corroborando com esse papel coadjuvante da temática ambiental, Marcovitch (2006, p.38) afirma que as "mudanças climáticas eram dadas como questões secundárias em face de outras, predominantemente questões militares. Por várias décadas, uma agenda sangrenta ocupou o tempo das lideranças". O mesmo autor escreve, tratando da necessidade de formar uma "agenda global positiva", que "se a globalização da economia foi o tema dominante no final do século XX, os riscos ambientais, ao lado dos riscos econômicos e dos riscos sociopolíticos, são temas que se impõem neste século inicial do terceiro milênio.” (MARCOVITCH, 2006, p.11).

Apesar da presença da temática ambiental nos fóruns e agendas locais, nacionais e internacionais, deve-se ter um olhar cético sobre a proeminência da ordem econômica sobre a da natureza, ao menos por enquanto. Nesse sentido, como exemplo mais contundente, observa-se que o resultado de diversos eventos globais de selo "verde" (Relatório Bruntdland, Rio 92, Tratado de Kyoto, Rio +10 , Rio +20 , etc.) não obstante todos os avanços de ordem ambiental ${ }^{7}$, apresentam questões geopolíticas e geoeconômicas como limitadores determinantes à plácida perspectiva de uma mudança de atitude da população mundial e, especificamente, dos seus agentes hegemônicos.

Definitivamente, essa é uma análise cética, porém não pessimista. Ratifica-se que o maior volume e precisão de conteúdo e o surgimento de novos fóruns e organizações ambientais dão à causa uma importância nunca antes conseguida. Concorda-se que

Não será fácil, insistimos, mesmo com os meios tecnológicos em processo ou já disponíveis, levar a sociedade a mudar velozmente suas atitudes, na forma de um consumo responsável, economia de recursos naturais, opção por um transporte não poluente e outros hábitos que somente uma educação contínua ensejará. Há que preservar, ainda, os valores humanos essenciais em qualquer agenda educacional. É perfeitamente viável harmonizá-los com os desafios das novas realidades". (MARCOVITCH, 2006, p.117).

Coadunada com as abrangentes discussões, a possível ação pulverizada da educação ambiental se apresenta como um instrumento central para enfrentar a atual crise. No texto final da conferência de Estocolmo 72 há o reconhecimento do "desenvolvimento da educação ambiental, como elemento crítico ao combate à crise ambiental no mundo", ela possuiria um "importante papel na geração dos debates e socialização do tema" (RAMOS, 1997, p.117).

É estimulante pensar nas escolas como centros de difusão de uma consciência ecológica, todavia os óbices são imensos, passando pelo interesse político na construção

6. Moraes (1997, p.33).

7. Avanços relacionados em diversas obras a exemplo de Ribeiro (2001), Marcovitch (2006) e Blanc (2012). 
do currículo à formação dos professores. $\mathrm{O}$ texto que segue se depara com esse desafio de pensar a educação ambiental no âmbito do Brasil e, em seguida, no caso prático do Sistema de Colégios Militares.

\section{Educação ambiental. Os caminhos dos Parâmetros Curriculares Nacionais (PCNs)}

A contínua mercantilização e coisificação do meio ambiente trouxeram consigo diversos problemas recentemente muito explorados pelo discurso ambientalista, a exemplo extinção de espécies animais e vegetais, dos refugiados ambientais (secas, enchentes, catástrofes diversas), das mortes por inanição, da extrema exclusão social (condições insalubres de vida), especialmente nas megacidades, do esgotamento de recursos naturais, da poluição de toda ordem (visual, sonora, atmosférica, das águas, do solo), do possível aquecimento global, etc.

A Educação Ambiental se apresenta como um catalisador para modificar essa relação entre homem e meio (este entendido como sociedade e natureza). Todavia, apesar da dispersão espacial, ou até por conta disso, não há de se esperar uma ação global e homogênea em direção à alfabetização ecológica, ao contrário, o desafio de assumir a importância desse veículo e instrumentalizá-lo, passa pela decisão de agentes de controle que, na definição de currículos, verticalizem as decisões política e ambientalmente adequadas a essa perspectiva ambiental.

Segundo Marcovitch (2006, p.114), "a educação, de modo mais amplo, e não apenas em nível universitário, assumirá um papel cada vez mais ativo na formação da consciência ambiental". Ratifica-se que esse é um ideal que perpassa pela aceitação de uma mudança de comportamento também nas várias esferas de gestão educacional e, mesmo, numa alteração de ordem metodológica e pedagógica.

Essa pretensa alteração não pode se restringir ao universo da gestão ou, mesmo dos muros da disciplina ou da unidade educativa, ela deveria vir acompanhada de uma mudança de comportamento para além da retórica. Num exercício, ainda que pontual, de pedagogia do exemplo. É, ao mínimo, interessante pensar num quadro hipotético em que as atividades de educação socioambiental, internalizadas pelos agentes (educadores e discentes) extrapolassem o universo material da escola, "contaminando" a família e a comunidade.

Concordando com Guattari (2005 [1990], p.35), é possível pensar no caminho educacional como "máquina de guerra" sustentada em micropolíticas e ações nos espaços do acontecer cotidiano, para enfrentar, local e globalmente, a partir do estabelecimento de novas solidariedades, esse problema que é de todos e que não será resolvido a partir do "universo das semióticas capitalíticas".

Migrando desse desejo utópico e pensando no cenário empírico do quadro da educação ambiental no Brasil, é necessário primeiramente desmistificar esse recente emblema de "guardião do verde" que foi colado ao país a partir da realização de eventos como o Rio 92 e Rio+20, ao discurso político em fóruns internacionais, à concessão de certificado ambiental para obras monumentais a exemplos dos estádios para os megaeventos, ao estímulo do uso de biocombustíveis e à crescente exploração do dito 
ecoturismo. Não obstante os trunfos que o Brasil possui associados à pretensa "Nova Ordem Ambiental", há muitas mazelas relacionadas a essa mesma ordem no nosso território, a exemplo das queimadas deliberadas no Cerrado, da "morte" de importantes rios, da permanência de uma "indústria da Seca", das metrópoles insustentáveis sob inúmeros vieses, do polêmico ${ }^{9}$ novo Código Florestal, dentre outros.

Ou seja, é nesse contexto e nesse país que estamos discutindo a necessidade de construir, verdadeiramente, uma estratégia de educação ambiental. Não dá para pensar em implementação de políticas deixando de ouvir o grito do território.

É nesse país dicotômico, com amplos abismos entre o discurso e a prática que temos avançado no tocante à Educação Ambiental. Assim nos mostra Ramos (1997, p.119-120) no breve histórico que faz, sustentado em análises de documentos, apontando o trato do assunto meio ambiente no currículo do ensino básico no Brasil.

É evidente que a temática ambiental é essencialmente interdisciplinar e, não obstante a orientação dos PCNs, como se verá a seguir, é trabalhado de forma fragmentada dentro dos currículos de disciplinas como Geografia, Biologia e Ciências. Esse é apenas um dos entraves que se soma às dificuldades na sensibilização e formação de professores, na implantação de atividades e projetos, na manutenção e continuidade dos já existentes, no tamanho e qualidade dos espaços escolares, no número de alunos e professores, na predisposição e capacitação dos docentes, na vontade da diretoria, dentre outros.

Malgrado todas as ressalvas feitas até então, é necessário pontuar que, ao menos no aspecto legal, houve um avanço sensível com a sansão da Lei de Diretrizes e Bases (Lei federal número 9.394/96) que versa e regula todos os níveis de educação do país e detalha conteúdos e procedimentos nos PCNs.

Esse excelente instrumento pedagógico, distribuído em todas as escolas do Brasil, detalha cada área de conhecimento (Língua Portuguesa, Matemática, Ciências Naturais, História, Geografia, Arte, Educação Física E Língua Estrangeira) além de apresentar orientações conceituais e metodologias para o trato dos temas transversais (Ética, Saúde, Meio Ambiente, Orientação Sexual E Pluralidade Cultural). Para o foco de análise deste artigo aqui desenvolvido, há, nos PCNs, três volumes de sensível interesse:

(1) O Volume 5 que trata da Geografia, notadamente dos enfoques conceituais na abordagem da disciplina para os quatro ciclos do Ensino Fundamental. Inicia o texto com uma importante recuperação da história da disciplina,

\footnotetext{
8. Ainda que passível de ponderação, Marcovitch (2006, p.99) relaciona vários desses trunfos brasileiros, como "os avanços na publicidade do tema pós redemocratização nos anos 1980; a constituição de organismos formais de controle e gestão ambiental como o Ministério do Meio Ambiente e Secretarias estaduais e municipais; o texto constitucional que prevê no artigo 225 que 'todos tem direito ao meio ambiente ecologicamente equilibrado, vem de uso comum do povo e essencial à sadia qualidade de vida, impondo-se ao poder público e à coletividade o dever de defende-lo e preserva-lo para as presentes e futuras gerações'; uma legislação repartida em agenda azul (recursos hídricos), marrom (resíduos sólidos) e verde (biomassa); a expansão das pesquisas científicas na área; o desenvolvimento de destinos de ecoturismo e a flexibilização das leis para desburocratizar a criação de reservas ambientais.
}

9. O texto final em pauta no Congresso Nacional possui claro padrão produtivista, atendendo aos anseios da bancada ruralista em detrimento às demandas ambientais. 
no meio acadêmico e no ensino, já apresentando um imenso abismo entre a discussão desenvolvida na academia e o exercício da prática no cotidiano das salas de aula. Este volume trás ainda orientações diversas de ordem pedagógica e metodológica para a construção do currículo da disciplina e o seu desenrolar letivo. Conforme orienta Moraes (1997, p.93), “a Geografia poderia servir como uma das alavancas para o desenvolvimento da temática ambiental nas Ciências Sociais".

(2) O Volume 9 apresenta dois dos temas transversais: Meio Ambiente e Saúde. Também é direcionado aos quatro ciclos da Educação Fundamental. Como instrumento de base, faz uma significativa apresentação da temática ambiental apresentando conceitos e sugestões de abordagem metodológica do tema. Defende a perspectiva da existência de um cenário de crise e sugere, através de educação ambiental, um posicionamento politicamente correto de toda a comunidade escolar.

(3) Considerando que a análise que se faz adiante sobre a Educação Ambiental no âmbito do Ensino Médio dos Colégios Militares, o Volume Ensino Médio, Capítulo 2 (Ciências Humanas e suas Tecnologias - Conhecimentos de Geografia) é o de maior interesse nessa breve análise dos PCNs.

Neste volume, apresenta-se a articulação entre os conceitos e os conteúdos e se sugere que a disciplina se debruce sobre as questões ambientais, sociais e econômicas resultantes dos processos de apropriação dos recursos naturais em diferentes escalas, grandes quadros ambientais do mundo e sua conotação geopolítica.

Há no texto dos PCNs, um esclarecimento significativo do papel da disciplina Geografia para o Ensino Médio:

No Ensino Fundamental, o papel da Geografia é "alfabetizar" o aluno espacialmente em suas diversas escalas e configurações, dando-lhe suficiente capacitação para manipular noções de paisagem, espaço, natureza, Estado e sociedade. No Ensino Médio, o aluno deve construir competências que permitam a análise do real, revelando as causas e efeitos, a intensidade, a heterogeneidade e o contexto espacial dos fenômenos que configuram cada sociedade.

$[\ldots]$

O Ensino Médio deve orientar a formação de um cidadão para aprender a conhecer, aprender a fazer, aprender a conviver e aprender a ser. Isto é, deve buscar um modo de transformar indivíduos tutelados e infantilizados em pessoas em pleno exercício da cidadania. (BRASIL, 1997, Ensino Médio, p.311).

$\mathrm{Na}$ aquisição dessa cidadania, indubitavelmente está inserida a necessidade de aprender a se relacionar com o outro e com o meio em que vive, sendo essa uma "deixa" essencial para a inclusão transversal da educação ambiental nos currículos do Ensino Médio. Conforme Ramos (1997, p.123), “o professor e a escola, são elementos que permeiam o processo de construção da 'consciência ambiental' e de um 'modus vivendi' mais compatível e/ou preocupado com a temática ambiental”. E, efetivamente, como se constata no texto dos PCNs, há o amparo legal para a ação. 


\section{Aproximações com a prática: o meio ambiente no ensino médio do Sistema Colégio Militar do Brasil}

O recorte do Ensino Médio se deu por opção metodológica. Seria inviável para o texto de um artigo uma análise dos planos do SCMB (Sistema Colégios Militares do Brasil) e, da mesma forma, abordar a temática em diversas frentes disciplinares. Assim, considerando o limite de uma análise em um texto dessa dimensão e que, nessa seção, pretende-se ilustrar a discussão teórica que se estabeleceu anteriormente com o estudo de caso de um sistema de alcance nacional, fez-se a opção pela avaliação dos Planos Curriculares de Geografia para os três anos do Ensino Médio.

O sistema de ensino dos colégios militares do Brasil é uma rede educacional submetida à Diretoria de Ensino Preparatório e Assistencial (DEPA), que, por sua vez, é subordinada ao Departamento de Educação e Cultura do Exército (DECEX). É considerado por essas instâncias como "um dos subsistemas de ensino do Exército e tem a seu cargo ministrar a educação básica nos níveis fundamental e médio" (DEPA, 27set2012).

Segundo o sítio oficial do órgão gestor, 0 primeiro Colégio Militar nasceu, pelo Decreto Imperial Nr.10.202, de 09 de março de 1889, com o nome de Imperial Colégio Militar da Corte, hoje o tradicional Colégio Militar do Rio de Janeiro.

Inicialmente estava destinado aos órfãos de militares tombados nos campos de batalha da Guerra do Paraguai. Com o passar do tempo o sistema cresceu e atende a civis e aos filhos de militares transferidos pelo território brasileiro e mesmo em missões no exterior (estes, possuem acesso aos CMs através das tecnologias de educação à distância). Atende assim às demandas assistencial e preparatória conduzindo o concludente do Ensino Médio para as Escolas Militares e para as diversas Universidades e Cursos Técnicos.

Atualmente são doze Colégios Militares, distribuídos nas cinco regiões do Brasil: Juiz de Fora/MG, Belo Horizonte/MG e Rio de Janeiro/RJ na região Sudeste; Santa Maria/RS, Porto Alegre/RS e Curitiba/PR na região Sul; Recife/PE, Salvador/BA e Fortaleza/CE na região Nordeste; Manaus/AM na região Norte; Campo Grande/MS e Brasília/DF na região Centro Oeste. Neles estão matriculados mais de 14.400 jovens, dos quais, segundo dados da DEPA (27set2012), 37\% são oriundos do meio civil, integrados ao sistema por meio de concurso público federal.

A proposta pedagógica dos Colégios Militares é definida e integrada nacionalmente e se subordinam aos valores, normas e prescrições do sistema de ensino do Exército e, ao mesmo tempo, procuram seguir as orientações da Lei de Diretrizes e Bases, vinculando-se assim às prerrogativas de princípios e finalidades da educação nacional.

Desta forma, além de valores tradicionais da caserna como respeito à disciplina, hierarquia, qualificação pelo mérito, dentre outros, estabelece-se também princípios e práticas que guardam relação com o esforço de modernização do ensino, implementado pelo Exército nos últimos cinco anos na esteira das orientações dos PCNs e mesmo do contexto sociotécnico da contemporaneidade.

O tema abordado por esse artigo é coerente com essa modernização do ensino, conforme destacado por esse órgão em sua página oficial: 
A delimitação de um núcleo central de conhecimentos privilegiando conteúdos significativos e essenciais para a vida dos alunos, com ênfase no desenvolvimento de competências básicas e habilidades “... que os permitam ter acesso ao conjunto de conhecimentos socialmente elaborados e reconhecidos como necessários ao exercício da cidadania" (PCN, 1998). A observância dos princípios da interdisciplinaridade e da contextualização, compreendendo os conhecimentos relacionados com os diversos contextos da vida dos alunos. (DEPA, 27set2012).

Apesar de não ser feita nenhuma referência específica relacionada à temática ambiental, ou mesmo à Educação Ambiental, acredita-se que, conforme argumentação alhures, esse grupo de conhecimentos compõe o "conjunto [...] necessário ao exercício da cidadania", formando o arcabouço de competências e habilidades que instrumentalizam o cidadão a se relacionar com o outro e com o meio em que vive.

Com esse entendimento, faz-se, a seguir a avaliação dos planos curriculares ${ }^{10} \mathrm{de}$ Geografia no âmbito dos anos letivos do Ensino Médio. Procura-se fundamentalmente identificar os assuntos específicos relacionados à temática ambiental.

O primeiro ano do Ensino Médio trabalha com assuntos da Geografia Geral, abordando no seu currículo elementos fisiográficos, humanos, econômicos e políticos. Na Unidade Didática I - "Localizando-se no Espaço" - e na Unidade didática IV - "O Espaço Mundial" - não aparece nenhum assunto relacionado à temática ambiental ou a Educação Ambiental.

Na Unidade Didática II - "O Espaço Natural” - aparecem alguns assuntos com possível interface com a temática ambiental, conforme Quadro 1.

Quadro 1. PLADIS de Geografia do $1^{\circ}$ Ano do EM, Unidade Didática II, Assuntos relacionados à temática ambiental.

\begin{tabular}{|l|l|c|}
\hline Assuntos & Objetivos Específicos & $\mathbf{N}^{\mathbf{0}}$ aulas* \\
\hline $\begin{array}{l}\text { 1. Estrutura e dinâmica da } \\
\text { Terra: }\end{array}$ & $\begin{array}{l}\text { h. Discutir a participação do homem como agente } \\
\text { modificador do relevo terrestre. }\end{array}$ & 05 \\
\hline $\begin{array}{l}\text { 2. As Superfícies líquidas: } \\
\text { - utilização dos recursos } \\
\text { hídricos e minerais. }\end{array}$ & $\begin{array}{l}\text { e. Explicar a importância das águas oceânicas e } \\
\text { continentais na vida dos povos e os efeitos prejudiciais } \\
\text { da poluição das massas líquidas. } \\
\text { i. Analisar o potencial das bacias hidrográficas } \\
\text { brasileiras quanto a sua capacidade energética, como } \\
\text { via de transporte. }\end{array}$ & 03 \\
\hline
\end{tabular}

10. No Sistema Colégio Militar do Brasil os planos curriculares do Ensino fundamental são denominados de PLAEST (Plano de Área de Estudo) e, no Ensino Médio, PLADIS (Plano de Disciplina) - essa terminologia mudará a partir de 2013. Eles são elaborados e revisados por comissões formadas por representantes de cada Colégio Militar sob a anuência da DEPA. Num período irregular, normalmente seguindo à demanda particular de cada disciplina, esse encontros acontecem com a finalidade de atualizar o currículo e discutir os interesses postos em pauta pelo corpo técnico de cada CM. 


\begin{tabular}{|l|l|c|}
\hline Assuntos & Objetivos Específicos & No aulas* \\
\hline $\begin{array}{l}\text { 5. Impactos ambientais: } \\
\text { - poluição atmosférica; }\end{array}$ & $\begin{array}{l}\text { a. Relacionar os principais problemas gerados pela } \\
\text { - eroãão e assoreamento; } \\
\text { - poluição dos recursos } \\
\text { hídricos; } \\
\text { - a questão da } \\
\text { biodiversidade. }\end{array}$ & $\begin{array}{l}\text { b. Explicar a importância de uma política de } \\
\text { desenvolvimento sustentável para os recursos naturais, } \\
\text { no uso racional do meio ambiente. }\end{array}$ \\
\end{tabular}

* O número de aulas é referente ao assunto, sendo que o objetivo específico deverá ser ministrado ao longo do número de aulas proposto, assim restam algumas horas para ministrar um tema de extrema importância.

Fonte: PLADIS, 27set2012.

Percebe-se na análise da Quadro 1 que, mais diretamente a temática em foco é abordada no Assunto 5 - "Impactos Ambientais" - todavia, são destinadas apenas três horas aulas para o trato desse tema. Isso certamente sinaliza a pouca importância dada ao assunto na construção do currículo.

Seguindo o mesmo critério, observa-se na Unidade Didática III - “O Espaço Geográfico" - apenas o seguinte assunto (Quadro 2).

Quadro 2. PLADIS de Geografia do $1^{\circ}$ Ano do EM, Unidade Didática III, assuntos relacionados à temática ambiental.

\begin{tabular}{|l|l|c|}
\hline Assuntos & Objetivos Específicos & $\mathbf{N}^{\mathbf{0}}$ aulas \\
\hline 4. O Espaço Rural: & $\begin{array}{l}\text { c. Descrever os impactos ambientais provocadas } \\
\text { pelas atividades extrativas e agropastoris no mundo. }\end{array}$ & 04 \\
\hline
\end{tabular}

Fonte: PLADIS, 27set2012.

Para o $2^{\circ}$ Ano do Ensino Médio o cenário é bem parecido. Ou seja, não há uma unidade específica que trate a temática ambiental, ficando à cargo do professor, na sua dinâmica cotidiana estabelecer as ligações sempre possíveis na análise da totalidade que é o espaço geográfico.

Neste ano letivo, aborda-se de forma mais direta a Geografia do Brasil, distribuída em todas as suas nuanças dentro das unidades didáticas.

Conforme referência acima há uma escassez de temas diretamente ligados à análise do meio ambiente, notadamente no tocante aos impactos da nossa contemporaneidade. Nas Unidades I - "O Espaço Brasileiro" -, III - O Espaço Agrário Brasileiro" -, IV - "A População e o Espaço Urbano Brasileiro" - e V - "A Regionalização Brasileira” - apesar das obvias ligações possíveis com os títulos das unidades, não aparece nos assuntos e objetivos específicos nenhuma interface direta com a temática ambiental. Apenas na Unidade Didática II - "O Espaço Natural" - há uma indicação direta ao tema, conforme Quadro 3. 
Quadro 3. PLADIS de Geografia do $2^{\circ}$ Ano do EM, Unidade Didática II,

Assuntos relacionados à temática ambiental.

\begin{tabular}{|l|l|c|}
\hline Assuntos & Objetivos Específicos & $\mathbf{N}^{\mathbf{0}}$ aulas \\
\hline 2. Os recursos naturais e & b. Analisar o aproveitamento econômico da vegetação & 07 \\
as atividades econômicas: & e suas conseqüências para o meio ambiente. \\
2.3. As grandes formações & c. Discutir a degradação dos recursos hídricos & \\
fitogeográficas brasileiras: & brasileiros. & \\
aproveitamento & & \\
econômico e a degradação & & \\
ambiental; & & \\
2.4. Os recursos hídricos: & & \\
\hline
\end{tabular}

Fonte: PLADIS, 27set2012.

Há para o terceiro ano dos Colégios Militares a prerrogativa de flexibilizar o currículo em vistas às necessidades de preparar o concludente para o enfrentamento do vestibular segundo as variáveis regionais, nesse sentido, a maior liberdade dá margem ao avanço ou recuo na abordagem da temática aqui tratada. Entretanto, é no PLADIS do terceiro ano que mais diretamente a temática ambiental aparece no currículo.

Especificamente no caso do Colégio Militar Brasília ${ }^{11}$, o plano curricular está dividido em duas frentes (A e B), sendo que os assuntos relacionados à Geografia Física são estudados somente na frente A e a questão ambiental é tratada no Pladis no $1^{\circ}$ semestre $/ 2^{\circ}$ bimestre, onde é abordada com a terminologia de "Mudanças climáticas e a questão ambiental".

É importante ressaltar que em todas as unidades há uma flexibilização com a proposta de que temas relativos à atualidade sejam abordados. Também são estabelecidas instruções metodológicas no PLADIS que permitem interlocuções interdisciplinares e adoção de material paradidático para assuntos específicos de sensível interesse, segundo a avaliação do corpo docente de Geografia de cada Colégio Militar. O limitador dessa possibilidade é a exiguidade de tempo para trabalhar um currículo conteudista numa carga horária reduzida para a disciplina (duas horas aulas semanais para o Ensino Médio).

Outra ressalva fundamental é que, ao passo que este artigo está sendo escrito, a Geografia está passando pelo seu momento de avaliação curricular dentro do Sistema Colégio Militar do Brasil e, pretende-se que, a partir do ano de 2013 sejam adotados novos planos curriculares com uma proposta educacional e terminologias mais adequadas às orientações da modernização do ensino, abordando não mais objetivos taxonômicos, mas habilidades e competências e estimulando o "diálogo" com outros campos disciplinares. É certo que essa medida pode redimensionar a análise que ora se faz, entretanto não a invialibiliza ou nega, visto que os atuais planos são utilizados desde $2001^{12}$, formando vários alunos no conjunto da nação.

11. Cf. site oficial (CMB, 27set2012).

12. Data da última revisão curricular de Geografia do SCMB. 


\section{Para continuar a discussão...}

$\mathrm{Na}$ fase final desse artigo, reafirma-se a certeza cimentada no corpo do texto de que, não obstante os mitos e dúvidas acerca do encaminhamento da temática ambiental, é certo que esse assunto interessa a todos os habitantes do planeta. Os avanços técnicos e as históricas relações de poder nos "jogos” políticos e econômicos, por vezes subverteram esses interesses ambientais locais e globais, repercutindo em crise.

Apresenta-se para a nossa contemporaneidade a encruzilhada de recuperar uma vivência menos impactante no planeta sem abrir mão dos avanços tecnológicos, do conforto e, por que não, do consumo. Esse hodierno cenário sugere um inarredável enfrentamento entre as demandas ambientais e uma lógica capitalista de organização social que se impõe agora e nos últimos séculos da humanidade.

É nesse cenário construído ao longo da passagem humana pela Terra e que, nos últimos anos da década de XX, ganharam visibilidade a partir do enunciado da crise ambiental de alcance planetário, que precisamos nos posicionar.

No tocante neste texto aqui desenvolvido, além de trazer à tona, mais uma vez, essa temática de interesse geral e supradisciplinar, propõe-se o seu enfrentamento (ao menos como uma estratégia) através da perspectiva educacional. A educação ambiental, pelo seu alcance multiescalar - direto na formação do cidadão e mais amplo na construção de um saber socialmente aceito - é certamente um caminho a ser seguido.

No caso empírico do Sistema Colégios Militares do Brasil, após a apresentação de dados e breve análise no último item desse artigo, convém retomar a discussão a fim de apontar outros avanços e recuos a partir dessa experiência concreta:

Tratando-se de um sistema educacional de alcance nacional, com multiplicidade de professores de origens e formações diversas, acredita-se que, apesar da relativa rigidez curricular determinada pelas instâncias hierarquicamente superiores, a prática pedagógica, a didática do cotidiano pode subverter a determinação do conteúdo e gerar infinitas possibilidades no trato do assunto. Assim, tendemos a acreditar que boa parte do discurso ambiental acontece para além do currículo numa relação invisível ao sistema que envolve um pacto relacional entre professores e alunos.

Parece evidente que a possibilidade supra mencionada tem algo de desejo inocente, assim cabe pensar no outro lado da mesma moeda. Ou seja, naquele grupo de docentes, também pertencentes aos Colégios Militares e de forma mais ampla às demais instituições públicas e privadas da educação nacional, que por inação ou severos limites na sua formação profissional, atendem cegamente às prerrogativas do planejamento curricular e do seu instrumento principal, o livro texto. Esse rígido trilho pedagógico abre possibilidades bastante limitadas de avanço no enfrentamento crítico e aprofundamento temático de qualquer assunto.

Pensando nas experiências pontuais e retomando o caso dos Colégios Militares, há de se destacar que, dentro do sistema, circulam notícias de experiências exitosas. A exemplo do estabelecimento de um plano de gestão ambiental e de iniciativas de coleta seletiva no Colégio Militar de Salvador e de um Trabalho Interdisciplinar desenvolvido 
no Colégio Militar de Brasília que ainda rende frutos à instituição e à comunidade. Nos dois casos, forma iniciativas de indivíduos que foram acatadas pelo comando do Colégio, ou seja, ações puntiformes associadas ao estímulo e formação profissional de docentes envolvidos com a temática ambiental.

Esse texto que ora se finda é um estudo inicial e com um recorte empírico ainda bastante limitado. Acredita-se que o aprofundamento da pesquisa possa apresentar outras experiências e, talvez, esperanças mais vívidas.

Como possibilidade de expansão da pesquisa aqui apontada, sugere-se a avaliação dos planos curriculares do Ensino Fundamental, mais amplo e de caráter formador, envolvendo, dentro do SCMB, formas mais lúdicas de trato disciplinar e, nesse sentido, apresentando outras possibilidades de abordagem da crise ambiental.

Também será possível abrir o leque de alcance do tema meio ambiente no âmbito do SCMB se se fizer a avaliação dos currículos das demais disciplinas que tradicionalmente abordam a temática, a exemplo da Ciências Físicas e Biológicas, Sociologia, Filosofia, História, Artes, Educação Física, dentre outras.

Como última ressalva, chama-se a atenção que este artigo está sendo apresentado no momento em que os planos curriculares estão passando por uma alteração significativa, dentro das disciplinas - como é o caso da Geografia - e no sistema como um todo, alterando terminologias e, principalmente, estratégias de abordagem aos assuntos.

No meio ao turbilhão de incertezas, inclusive quanto ao futuro material da humanidade no planeta, esse artigo reafirma a necessidade de se discutir e, especialmente, se posicionar frente às emergenciais demandas ambientais. A apresentação da educação como um viés de enfrentamento e os dados do Sistema Colégio Militar do Brasil são apenas prenúncios da discussão necessária que, esperamos, segue.

\section{Referências}

BECKER, Berta K. Amazônia: geopolítica na virada do III milênio. Rio de Janeiro: Gramond, 2007.

BLANC, Cláudio. Aquecimento Global e crise ambiental. São Paulo: Gaia, 2012.

BRASIL. Ministério de Educação e do Desporto. Parâmetros Curriculares

Nacionais. Brasília/DF: Secretaria de Educação, 1997.

CARVALHO, Marcos Bernardino de. A Natureza na Geografia do Ensino Médio. In: OLIVEIRA, Ariovaldo U. de. Para onde vai o ensino de Geografia? $5^{\text {a }}$ ed. São Paulo: Contexto, 1994, p.81-108.

CMB (Colégio Militar de Brasília). Ministério da Defesa. Exército Brasileiro. Prevest. Disponível em: www.cmb.ensino.eb.br/. Acesso em: 27 set2012.

GUATTARI, Félix. As três ecologias. Trad. Maria C.F. Bittencourt. 16 ${ }^{\mathrm{a}}$ ed. Campinas, SP: Papirus, 2005. [1 $1^{\mathrm{a}}$ ed. 1990]. 
DEPA (Diretoria de Ensino Preparatório e Assistencial). Ministério da Defesa. Exército Brasileiro. Sistema Colégio Militar do Brasil. Disponível em: http://www.depa. ensino.eb.br/pag_sistemaCM.htm. Acesso em: 27set2012.

MARCOVITCH, Jacques. Para mudar o futuro: mudanças climáticas, políticas públicas e estratégias empresariais. São Paulo: EDUSP: Editora Saraiva, 2006.

MORAES, Antonio Carlos Robert. Meio Ambiente e Ciências Humanas. $2^{\text {a }}$.ed. São Paulo: Hucitec, 1997. [1 ${ }^{\mathrm{a}}$ ed. 1994].

PLADIS (Plano de Disciplina). Sistema Colégio Militar do Brasil. Geografia Ensino Médio. Colégio Militar de Curitiba. Disponível em: http://www.cmc.ensino.eb.br/novo/ images/pdf/PLADIS/1SERIE/geo1sem2001.pdf. Acesso em: 27set2012.

RAMOS, Marcos Lupercio. A temática ambiental: "Um problema” das sociedades contemporâneas?. In: Caderno Prudentino de Geografia. N.19/20. Geografia, Movimentos Sociais, Natureza. Presidente Prudente/SP: AGB, nov.1997, p.104-127.

RIBEIRO, Wagner Costa. A ordem ambiental internacional. São Paulo: Contexto, 2001.

SANTOS, Milton. Natureza. Salvador: CRA, 2007, p.31-44. [Transcrição da aula inaugural da FFLCH da USP em nov.1992].

Adriano Bittencourt Andrade

Mestre em Geografia pela Universidade Federal da Bahia e doutor em Arquitetura e Urbanismo pela Universidade Federal da Bahia. Desde 2014 faz estágio de PósDoutoramento no Departamento de Geografia da UNB. É professor do Colégio Militar de Brasília.

Endereço: SQN, 102 C, ap.506, Brasília/DF. 6133270352 / 6184764201

E-mail: abittandrade@hotmail.com

Cláudia Cristina Silveira da Luz

Licenciada em Geografia pela Universidade Católica de Brasília e professora da secretaria de educação do Governo do Distrito Federal e do Colégio Militar de Brasília.

Endereço: SQN, 102 C, ap.506, Brasília/DF. 61 9215-1090

claudiakauluz@gmail.com

Recebido para publicação em novembro de 2014 Aprovado para publicação em agosto de 2015 